EMBRYARIDDLE
Aeronautical University

SCHOLARLY COMMONS

\section{International Journal of Aviation,} Aeronautics, and Aerospace

\title{
Collegiate Aviation Pilots: Analyses of Fatigue Related Decision- Making Scenarios
}

Julius Keller

Purdue University, keller64@purdue.edu

FLAVIO COIMBRA MENDONCA MR

Purdue University, coimbraf@erau.edu

Jason E. Cutter

Purdue University, cutterj@purdue.edu

Follow this and additional works at: https://commons.erau.edu/ijaaa

Part of the Human Factors Psychology Commons

\section{Scholarly Commons Citation}

Keller, J., MENDONCA, F. C., \& Cutter, J. E. (2019). Collegiate Aviation Pilots: Analyses of Fatigue Related Decision-Making Scenarios. International Journal of Aviation, Aeronautics, and Aerospace, 6(4).

https://doi.org/10.15394/ijaaa.2019.1360

This Article is brought to you for free and open access by the Journals at Scholarly Commons. It has been accepted for inclusion in International Journal of Aviation, Aeronautics, and Aerospace by an authorized administrator of Scholarly Commons. For more information, please contact commons@erau.edu. 
Collegiate Aviation Pilots: Analyses of Fatigue Related Decision-Making Scenarios

\section{Cover Page Footnote}

The researchers of the current study would like to thank the participants and organization for the feedback and support. 


\section{Introduction}

Fatigue is a human factor that reduces pilot performance and may lead to incidents and accidents (Caldwell, 2005; Caldwell et al., 2009). Even though fatigue may be difficult for investigators to link to an incident or accident, it is known to be problematic (Dawson \& McCulloch, 2005). Fatigue may have been an important latent condition for many of the approximately 23,800 general aviation (GA) accidents during the past 17 years but not necessarily identified as a probable cause. Additionally, events that missed a detrimental situation due to fatigue often go unnoticed and or unreported. Even without exact numbers, it is important to continue to address the issue. The National Transportation Safety Board (NTSB) (2019) periodically releases the Most Wanted List of Transportation Safety Improvements. This list highlights critical threats to safety in transportation and provides recommendations to mitigate such risks. The reduction of fatigue-related accidents has been listed since 2016 (NSTB, 2019). Based on continuing safety promotion efforts within the aviation community, it is important to understand fatigue from multiple perspectives. In general, the causes and symptoms of fatigue as well as mitigation is well known.

Fatigue is generally the outcome of one or more factors that include inadequate food and/or fluid intake, mental and physical workload, and disrupted or lack of sleep (Caldwell et al., 2009). According to the International Civil Aviation Organization (ICAO), adequate sleep is the most efficient strategy to mitigate fatigue (ICAO, 2012). Several other strategies can also assist in mitigating the risk of aircraft accidents due to the insidious effects of pilots' fatigue (Gander et al., 2013). However, most of the current literature related to fatigue and pilots is focused on Part 121 operators. Moreover, collegiate aviation pilots often face issues much different than found in Part 121 or military flight operations. Collegiate aviation pilots often are enrolled in five or six courses per semester which requires completion of homework and studying. Many participate in extracurricular activities such as student organizations, sports, social activities, and work part-time jobs. Often, a student's "duty day" can exceed 14 hours. Along with a rigorous schedule, students may feel pressures or emotional strain unrelated to academics. Students are away from home for the first time, have relationship issues, and are developing coping skills for life issues (Mendonca, Keller, \& Lu, in press). Additionally, according to Mendonca et al. (in press), 116 or $85 \%$ of the collegiate aviation pilot sample at one midwestern university indicated fatigue influenced the quality of their flight training.

Furthermore, extant research focused on general aviation pilots including flight students and instructors, typically utilize surveys as research instruments. For example, McDale and Ma (2008) used a survey questionnaire to investigate how CFR Part 141 flight instructors perceive fatigue as well as the impact of 
fatigue in flight training. A finding of concern was that flight instructors were not well versed on the detrimental effects of fatigue during flight training.

Though surveys are useful, the method proposed in this paper may assist in gaining a clearer understanding of how collegiate aviation pilots perceive fatigue, utilize mitigation strategies, and make decisions is useful for research, training, and policy implementation. The purpose of the current paper is to investigate fatigue identification and management by CFR Part 141 pilots utilizing decision-making scenarios. These scenarios, which were designed based upon decision-making concepts and empirical data on fatigue in aviation (Caldwell, 2005; Caldwell \& Caldwell, 2016; Civil Aviation Safety Authority [CASA], 2012; ICAO, 2012; Federal Aviation Administration [FAA], 2016; Mendonca et al., in press). This exploratory study investigated ways to understand pilot mitigation strategies, pressures, and reasons for go-no-go decisions involving CFR Part 141 pilots. The use of decision-making scenarios has not been seen in the extant literature and may provide another research perspective. A thematic analysis was utilized to gain a clearer understanding of the responses.

\section{Fatigue and Decision-Making}

\section{Literature Review}

Fatigue is a ubiquitous and normal aspect of life (FAA, 2007). For many people fatigue is only a disturbance that can be solved with a good night of sleep, a break in a specific activity that brought it on, or even a short nap. In these cases, fatigue will rarely lead to undesired consequences. However, improperly identified and managed fatigue could lead to disastrous consequences in aviation (Caldwell et al., 2001). Fatigue is a multidimensional construct, associated with multifaceted life and work factors, including the safety culture of the organization (Avers \& Johnson, 2011; Fletcher, Hooper, Dunican, \& Kogi, 2015), for which no single-mitigation strategy will be effective (Caldwell et al., 2009). According to Sieberichs and Kluge (2016), fatigue can be subdivided in emotional, mental, and physical. In addition, its effects vary among different individuals. ICAO (2012) defines fatigue as

a physiological state of reduced mental or physical performance capability resulting from sleep loss or extended wakefulness, circadian phase, or workload (mental and/or physical activity) that can impair a crew member's alertness and ability to safely operate an aircraft or perform safety-related duties. (p. xii)

Continued engagement on cognitively challenging tasks often leads to a subjective state labeled cognitive fatigue (Lorist et al., 2000; Meijman, 1991). Although cognitive fatigue is a complex, multifaceted state involving various negative outcomes, it is widely accepted that reduced motivation and effort are one of its primary aspects (van der Linden, 2011). Accordingly, there is 
agreement among scholars that performance deficiencies are likely to result in a combination of reduced capacity and reduced motivation to perform (Hockey, 1997; Kanfer \& Ackerman, 1989; Meijman, 1991).

Several studies have indicated an evidence between increasing fatigue and increments of human-error rates, decrements in cognitive functions, reduced situational awareness and effective performance (Caldwell, 2005; Dawson, Chapman, \& Thomas, 2012; Dawson \& McCulloch, 2005; Mendonca et al., in press; Petrie, Powell, \& Broadbent, 2004), and impaired neurobehavioral performance (Greeley et al., 2013). Additionally, Williamson and Feyer (2000) investigated the relationships between moderate sleep deprivation, cognitive, and motor performance. The researchers also compared the differences between those who were under the influence of alcohol. The researchers tested participants reaction time, hand-eye coordination, grammatical reasoning, tiredness, and memory. Results indicated that after being awake for 17-19 hours, performance levels were equivalent to a blood alcohol content of .05 percent. A .05 percent blood alcohol content is the legal limit for driving in some states such as Utah. For commercial drivers and pilots, the limit is .04. However, the Federal Aviation Regulations mandate pilots not fly if under the influence of alcohol. Hypothetically, a person could have a .00 BAC level and be under the influence by having symptoms associated with drinking such as a "hangover." Williamson and Feyer (2000) concluded at the end of their study that sleep deprivation clearly has a detrimental effect on mental processing equivalent to being intoxicated. The understanding of the consequences of fatigue supports the theory that there could be a reduction in the quality of flight training and unnoticed errors. Fatigue influences cognitive functions such as retention of knowledge or learning.

In a study that examined the relationship between stress, fatigue, and cognitive functioning, researchers utilized college students as participants (Palmer, 2013). The researcher assessed college-aged students to determine their cognitive strength under different levels of stress and fatigue. Results indicated fatigue and stress remained a significant factor in learning. Palmer (2013) argued that stress and fatigue could have detrimental effects on learning and cognitive functions. Recommendations included attentiveness to the importance of healthy sleep quantity, quality, coping, and stress as part of the curriculum. Fortunately, within aviation curricula there is emphasis of human factors including fatigue. Nevertheless, uncertainty remains within the effectiveness of these elements in relation to practical application. Program administrators can mandate specific hours of rest and monitor student sleep, but this is extremely impractical at best.

Within the collegiate environment, if a student to arrives at flight lessons fatigued, it is possible that the ability to learn all the information will be compromised. Students not learning all the information taught about flying may cause them to be unprepared for future flights, which increases risks and costs. 
The previous article makes a point when mentioning the need for colleges to put more emphasis on the importance of taking better care of themselves to avoid being fatigued and the significance of management's role.

A research project by Mendonca et al. (in press) investigated CFR Part 141 collegiate aviation students' self-awareness of their fatigue issues; the possible causes of fatigue afflicting those students; their lifestyle as well as their perceptions of personal solutions to fatigue. Findings of this study indicated that fatigue is a safety hazard during flight training, and that the students' lifestyles are not conducive to mitigating fatigue. In addition, findings of this study also indicated that pilots had made mistakes during flight activities because of being fatigued. High workload due to academic and flight activities were two important factors contributing to fatigue. Healthy lifestyle choices, that include physical activities, a balanced diet, adequate sleeping habits, and the use of effective time management strategies are behaviors that could help mitigate fatigue (CASA, 2012). Interestingly, only $49 \%$ of the respondents indicated they regularly engaged in physical activities. Moreover, issues in their sleep environments (e.g., loud neighbors; improper temperature) were factors disrupting their sleep. Yet, excessive use of electronics prior to bed was a major factor impacting the quality and quantity of sleep of CFR Part 141 pilots. Mendonca et al. suggested that based upon their findings, further studies investigate the Part 141 collegiate aviation pilots' aeronautical decision-making process using fatigue-related scenarios.

\section{Fatigue Countermeasures}

The most effective fatigue mitigation is adequate sleep (FAA, 2007; Lee $\&$ Kim, 2018). According to the Flight Safety Foundation (2009), recommendations for practice include waking up and going to bed the same time every day in a location meant for sleeping only. This practice can both improve the quantity and quality of sleep. It is also suggested not performing any strenuous activities prior to bedtime. Additionally, one should not consume alcohol, large food quantities, nicotine, and or caffeine before sleeping. Furthermore, it is recommended that if there is trouble falling asleep, a person should remove themselves from the sleep area, do something relaxing then make another attempt to sleep (CASA, 2012; Flight Safety Foundation, 2009; ICAO, 2016). In conjunction with proper sleep habits, a healthy lifestyle should be a priority. This includes proper diet, exercise, and stress management. If a person feels the effects of fatigue while working, one can use strategic napping.

Some sleep is better than no sleep at all. According to Caldwell et al. (2009) and Petrie et al. (2004), controlled napping prior to a duty (especially a night duty), and even during the flight (if permitted and safe) could restore alertness and improve reaction speed, with a positive impact on aviation safety. Napping is the most effective nonpharmacological strategy to enhance the pilot's 
situational awareness (Caldwell et al., 2009; Rosekind et al., 1992). However, aviators should be cautious with the risks associated with sleep inertia (Caldwell et al., 2009; ICAO, 2012, 2016). Sleep inertia is the state of cognitive and sensory degradation right after waking. The body responses associated with sleep inertia are disorientation, drowsiness, and degraded motor dexterity. This is caused by the sleep cycles. Individuals should be aware of how sleep cycles or length of naps can affect the significance of sleep inertia (Tassi \& Muzet, 2000). It is important to note that napping is not a solution for chronic fatigue. A person should see a doctor to determine if there is a significant health issue such as sleep apnea or insomnia.

If a people find themselves effected by acute fatigue symptoms, strategic caffeine use may be appropriate with caution. Caffeine can be used to reduce sleepiness but only temporarily. According to Caldwell and Caldwell (2016), the effects of caffeine can differ for each person. It typically takes 30 minutes for caffeine to become effective and may last for more than five hours. Caffeine should only be used when alertness is low. For example, instead of using caffeine prior to a long duty day, it should be used more towards the end (Caldwell \& Caldwell, 2016). Even with a healthy lifestyle and attentiveness to fatigue countermeasures, fatigue remains a complex issue.

As previously noted, fatigue is associated with multiple factors (Avers \& Johnson 2011; ICAO, 2016). Moreover, the way persons identify and/or cope with fatigue generally vary (Caldwell \& Caldwell, 2016; ICAO, 2012; Mendonca et al., in press; Petrie et al, 2004). Fatigue cannot be successfully overcome with a single strategy, such as training and education. In fact, solutions are not straightforward (Dawson et al., 2012). According to Dawson and McCulloch (2005), and Fletcher et al. (2015), an effective approach to fatigue management in the flight deck requires a variety of risk mitigation strategies involving multiple stakeholders, including pilots. Studies addressing fatigue mitigation frequently occur in a laboratory setting, thus they may not work as well in the aviation environment (Fletcher et al., 2015). Adequate quantity and good quality sleep are likely the most effective way to reduce fatigue (FAA, 2007) However, other strategies can contribute to this process (Caldwell et al., 2009; CASA, 2012; ICAO, 2012). Most research studies addressing fatigue in aviation have either involved Part 121 pilots (Gander et al., 2013; Goode, 2003; Honn et al., 2016; Petrie et al., 2004; Petrie \& Dawson, 1997; Sieberichs \& Kluge, 2016) or military pilots (Caldwell et al., 2001; Caldwell \& Brown, 2003; Caldwell et al., 2000; Miller \& Melfi, 2006).

There is a paucity of research involving the GA community. There are some differences across aviation sectors. However, Part 121, military, and GA pilots are constantly confronted with situations that may cause performance reducing and other cognitive issues due to fatigue. The causes and symptoms of 
fatigue are consistent across an array of aviation operations (Avers \& Johnson, 2011; Caldwell, 2005; Caldwell \& Caldwell, 2016). The purpose of this study was to examine six fatigue related decision-making scenarios. The primary focus of the analysis was to determine the reasons for go-no-go decisions and reported mitigation strategies among collegiate aviation pilots.

\section{Participants}

\section{Method}

CFR Part 141 programs are FAA approved and periodically audited by the Agency. According to the FAA (2016), enrollment in a 14 CFR Part 141 program will ensure quality, safety, efficiency, and continuity due to a structured approach to flight training. The target population for this study was flight personnel enrolled in selected classes at Midwestern collegiate aviation flight program. Participants were eligible to participate in this study if they were at least 18 years old, a pilot, and if they had flown in the previous six months. It is important to note that in a university environment, electronic devices are easily accessible, thus ensuring that the target population would have the means to participate in a webbased survey. The population for this study was approximately 100 pilots.

\section{Research Instrument and Procedures}

Researchers of this study created six fatigue related decision-making scenarios. Scenarios were selected to reflect real-world situations collegiate aviation pilots could relate to. A pilot test of the scenarios was conducted with six faculty members who teach aviation related courses at the target university and who are also experienced pilots, and with 10 certified flight instructors from the same university. Researchers asked them to review the assessment instrument for content, organization, grammar, appropriateness, and syntax. Researchers then made the necessary modifications, following their suggestions. Findings from Mendonca et al. (in press) were also utilized while developing the scenarios. Additionally, accidents case studies were referenced to add another component of relatedness. Each scenario included events which could cause mental and or physical fatigue. Additionally, there were internal and external pressures included. Once the scenarios were created, the research sought subject matter experts to assist in revisions. After several rounds of revisions, the scenarios were copied into Qualtrics@. Once Institutional Review Board (IRB) approval was obtained, the research instrument was distributed to selected courses within the flight program. The classes were 200,300, and 400 levels. After the informed consent process was completed, participants were prompted to respond truthfully to each scenario and provide in depth explanations for the go-no-go decision. At the end of the scenarios, a demographics section included: age, gender, enrollment status, certificates and ratings held, and approximate total flight hours. The scenarios were open for responses for two weeks in October 2018. Researchers planned to 
use a thematic analysis on the qualitative data. Table 1 shows each of the six scenarios.

Table 1

Six-fatigue related decision-making scenarios

\begin{tabular}{|c|c|}
\hline Scenario & Description \\
\hline $\begin{array}{l}\text { 1. Lack of } \\
\text { sleep and } \\
\text { stress }\end{array}$ & $\begin{array}{l}\text { You were restless because of stress and only got } 4 \text { hours of sleep } \\
\text { because of two upcoming midterms and a checkride. After your } \\
\text { two midterms, you find it difficult to concentrate, are careless, and } \\
\text { repetitively yawning. Your checkride is in two hours. Do you } \\
\text { proceed with your checkride? Why or why not? Please explain. }\end{array}$ \\
\hline $\begin{array}{l}\text { 2. Lack of } \\
\text { sleep but } \\
\text { feels } \\
\text { prepared }\end{array}$ & $\begin{array}{l}\text { You were unexpectedly called to move your checkride to the } \\
\text { current day because of a cancellation. It was previously scheduled } \\
\text { for } 7 \text { days in the future. The forecast indicates poor weather in } 7 \\
\text { days. You are well prepared with your knowledge, procedures, } \\
\text { and confident you will pass. Last night you were socializing with } \\
\text { friends and did not get much rest. Do you agree with moving your } \\
\text { checkride and proceeding? Why or not? Please explain. }\end{array}$ \\
\hline $\begin{array}{l}\text { Significant } \\
\text { weather } \\
\text { delay } \\
\text { while on } \\
\text { cross- } \\
\text { country }\end{array}$ & $\begin{array}{l}\text { You are out flying a three-legged trip. Before the third leg you } \\
\text { experienced a delay due to unforecasted weather conditions which } \\
\text { lasted five hours. What was expected to be a four-hour trip now } \\
\text { has lasted more than } 10 \text { hours. You are exhausted when the } \\
\text { weather clears up for your 2-hour return flight. Do you proceed to } \\
\text { your destination? Why or why not? Please explain. }\end{array}$ \\
\hline $\begin{array}{l}\text { 4. Lack of } \\
\text { sleep and } \\
\text { family } \\
\text { issues }\end{array}$ & $\begin{array}{l}\text { You are doing very well with your flight activities and course } \\
\text { work. However, recently, you have been dealing with family } \\
\text { problems and have not slept well for the last three nights over the } \\
\text { weekend. Your flight lesson is Monday morning and you have a } \\
0730 \text { slot. Do you proceed with your flight lesson? Why or why } \\
\text { not? Please explain. }\end{array}$ \\
\hline $\begin{array}{l}\text { 5. Part- } \\
\text { time job } \\
\text { schedule } \\
\text { change } \\
\text { and lack } \\
\text { of sleep } \\
\text { but has a } \\
\text { 4-hour nap }\end{array}$ & $\begin{array}{l}\text { Finals week has begun, and your part-time job manager has asked } \\
\text { you to work extra hours. You agreed because of the extra pay. } \\
\text { Studying, examinations, and work have caused you to get } \\
\text { approximately } 3 \text { hours of sleep each night for the past four nights. } \\
\text { You are fatigued. However, you have a night cross country flight } \\
\text { ( } 2.5 \text { hours) coming up. You have a window of nothing scheduled } \\
\text { and can sleep } 4 \text { hours prior to the night flight. Do you proceed } \\
\text { with the flight? Why or why not? Please explain. }\end{array}$ \\
\hline $\begin{array}{l}\text { 6. Physical } \\
\text { fatigue }\end{array}$ & $\begin{array}{l}\text { You were able to get a good night's rest and woke up refreshed at } \\
0800 \text {. Your only academic task for the day is a night cross country }\end{array}$ \\
\hline
\end{tabular}




\begin{tabular}{l|l}
$\begin{array}{l}\text { and +14- } \\
\text { hour day- } \\
\text { night } \\
\text { cross- } \\
\text { country }\end{array}$ & $\begin{array}{l}\text { (2.5 hours) at } 2100 \text { local. A friend calls for help to move } \\
\text { apartments. You agree because she will pay you } \$ 100.00 . \text { For a } \\
\text { late carrying furniture up and down stairs. Once you finished } \\
\text { helping, you get a flat tire on the way home. It takes a while to fix. } \\
\text { You have 1 hour before your flight. Once you get to the hangar } \\
\text { you find out your aircraft will not be back until } 2200 \text { local. Do you } \\
\text { proceed with your night cross country? Why or why not? Please } \\
\text { explain. }\end{array}$ \\
\hline
\end{tabular}

\section{Demographics}

\section{Results}

In total, forty-six $(n=46)$ participants responded to the invitation to participate. However, not all fully completed each scenario and or demographic section. The specifics for each scenario will be reported later in this section. Thirty-five participants completed the demographics section. Thirty-one (88.57\%) were between the ages of 18 and 25 while four (11.43\%) were between 26 and 35 . Twenty-eight $(80 \%)$ of the participants were male, six $(17.14 \%)$ were female, and one $(2.86 \%)$ preferred not to say. Three $(8.57 \%)$ of the participants were freshman, eleven $(31.43 \%)$ were sophomores, eight $(22.86 \%)$ were juniors, five $(14.29 \%)$ were seniors, five $(14.29 \%)$ were graduate students, two $(5.71 \%)$ were enrolled in the combined degree program, and one $(2.86 \%)$ responded as other. Majority of the participants held private, commercial, and instrument certificates/ratings. A smaller number held Certified Flight Instructor (CFI), Certified Flight Instructor - Instrument (CFII), Multi-Engine Instructor (MEI), Airline Transport Pilot (ATP), and remote pilot certificates/ratings. Twenty-seven (77.14\%) participants indicated less than 250 total hours logged, five (14.29\%) had between $250-500$ total hours, and three $(8.57 \%)$ indicated having between 501-1000 total logged hours. 


\section{Analysis Go and No-Go Decisions}

\section{Table 2}

Fatigue related decision-making scenarios results summary

\begin{tabular}{|c|c|c|c|c|c|}
\hline \multirow[t]{2}{*}{ Scenario } & \multirow{2}{*}{$\begin{array}{l}\text { Number } \\
\text { of } \\
\text { responses }\end{array}$} & \multicolumn{2}{|c|}{ Would you proceed? } & \multirow{2}{*}{$\begin{array}{c}\text { Sample Go } \\
\text { Decision } \\
\text { Quotation }\end{array}$} & \multirow{2}{*}{$\begin{array}{c}\text { Sample No- } \\
\text { Go } \\
\text { Decision } \\
\text { Quotation }\end{array}$} \\
\hline & & Yes & No & & \\
\hline $\begin{array}{l}\text { 1. Lack of } \\
\text { sleep and } \\
\text { stress }\end{array}$ & $(n=42)$ & $7(16.67 \%)$ & $\begin{array}{c}35 \\
(83.33 \%)\end{array}$ & $\begin{array}{l}\text { I would feel } \\
\text { pressure to } \\
\text { continue with } \\
\text { the checkride } \\
\text { since it has } \\
\text { already been } \\
\text { scheduled. I } \\
\text { would feel bad } \\
\text { if I was the } \\
\text { reason it had to } \\
\text { be } \\
\text { rescheduled. }\end{array}$ & $\begin{array}{l}\text { I am not fit } \\
\text { to be } \\
\text { flying, let } \\
\text { alone } \\
\text { taking my } \\
\text { checkride. } \\
\text { Being a } \\
\text { good pilot } \\
\text { begins with } \\
\text { making } \\
\text { good } \\
\text { decisions } \\
\text { and my } \\
\text { DPE will } \\
\text { understand. } \\
\text { For me, my } \\
\text { life and } \\
\text { safety are } \\
\text { more } \\
\text { important } \\
\text { than } \\
\text { money. }\end{array}$ \\
\hline $\begin{array}{l}\text { 2. Lack of } \\
\text { sleep but } \\
\text { feels } \\
\text { prepared }\end{array}$ & $(n=39)$ & $22(56.41 \%)$ & $\begin{array}{l}17 \\
(43.59 \%)\end{array}$ & $\begin{array}{l}\text { I typically } \\
\text { function quite } \\
\text { well without a } \\
\text { lot of sleep; if I } \\
\text { am well- } \\
\text { prepared for } \\
\text { my checkride } \\
\text { then sleeping a } \\
\text { bit less } \\
\text { shouldn't affect } \\
\text { me too much. }\end{array}$ & $\begin{array}{l}\text { I would ask } \\
\text { to move the } \\
\text { checkride } \\
\text { to another } \\
\text { day. While } \\
\text { I may be } \\
\text { prepared } \\
\text { with my } \\
\text { knowledge } \\
\text { and skill, I } \\
\text { am not }\end{array}$ \\
\hline
\end{tabular}




\begin{tabular}{|c|c|c|c|c|c|}
\hline & & & & & $\begin{array}{l}\text { physically } \\
\text { fit to fly }\end{array}$ \\
\hline $\begin{array}{l}3 . \\
\text { Significant } \\
\text { weather } \\
\text { delay } \\
\text { while on } \\
\text { cross- } \\
\text { country }\end{array}$ & $(n=37)$ & $12(32.43 \%)$ & $25(67.57 \%)$ & $\begin{array}{l}\text { I need to get } \\
\text { back. }\end{array}$ & $\begin{array}{l}\text { Get home } \\
\text { itis is a } \\
\text { very real } \\
\text { danger in } \\
\text { this } \\
\text { scenario } \\
\text { and with } \\
\text { the bad } \\
\text { weather } \\
\text { that was in } \\
\text { the area, I } \\
\text { would not } \\
\text { risk it. }\end{array}$ \\
\hline $\begin{array}{l}\text { 4. Lack of } \\
\text { sleep and } \\
\text { family } \\
\text { issues }\end{array}$ & $(n=37)$ & $11(29.73 \%)$ & $26(70.27 \%)$ & $\begin{array}{l}\text { I might not be } \\
\text { flying at my } \\
\text { best, but there } \\
\text { will be an } \\
\text { instructor to } \\
\text { keep me safe } \\
\text { and I'm sure } \\
\text { that I'll still } \\
\text { learn } \\
\text { something } \\
\text { either way. }\end{array}$ & $\begin{array}{l}\text { If I am } \\
\text { doing well } \\
\text { in my flight } \\
\text { course and } \\
\text { am ahead } \\
\text { or on track } \\
\text { to finish, } \\
\text { canceling } \\
\text { one slot for } \\
\text { fatigue, } \\
\text { especially } \\
\text { emotionally } \\
\text { induced } \\
\text { fatigue, is a } \\
\text { good idea. }\end{array}$ \\
\hline $\begin{array}{l}\text { 5. Part- } \\
\text { time job } \\
\text { schedule } \\
\text { change } \\
\text { and lack } \\
\text { of sleep } \\
\text { but has a } \\
\text { 4-hour nap }\end{array}$ & $(n=35)$ & $15(42.85 \%)$ & $20(57.14 \%)$ & $\begin{array}{l}4 \text { hours of } \\
\text { sleep is a good } \\
\text { nap }\end{array}$ & $\begin{array}{l}\text { I don't } \\
\text { sleep well } \\
\text { during the } \\
\text { day, so I } \\
\text { doubt that a } \\
\text { 4-hour nap } \\
\text { would be } \\
\text { enough to } \\
\text { overcome } \\
\text { the fatigue } \\
\text { of sleep }\end{array}$ \\
\hline
\end{tabular}




\begin{tabular}{|c|c|c|c|c|c|}
\hline & & & & & $\begin{array}{l}\text { deprivation. } \\
\text { Night cross } \\
\text { countries } \\
\text { require } \\
\text { more } \\
\text { brainpower } \\
\text { than I can } \\
\text { muster } \\
\text { when sleep } \\
\text { deprived, } \\
\text { so I will } \\
\text { reschedule. }\end{array}$ \\
\hline $\begin{array}{l}\text { 6. Physical } \\
\text { fatigue } \\
\text { and }+14- \\
\text { hour day- } \\
\text { night } \\
\text { cross- } \\
\text { country }\end{array}$ & $(n=35)$ & $16(45.71 \%)$ & $19(54.29 \%)$ & $\begin{array}{l}\text { You have had } \\
\text { ample rest and } \\
\text { food and are } \\
\text { ready to fly it } \\
\text { is only one } \\
\text { hour past your } \\
\text { original } \\
\text { departure time. }\end{array}$ & $\begin{array}{l}\text { I try to } \\
\text { stick to an } \\
\text { informal } \\
\text { "three } \\
\text { strikes, } \\
\text { you're out" } \\
\text { policy. } \\
\text { Strike 1) } \\
\text { hard move. } \\
\text { Strike 2) } \\
\text { flat tire. } \\
\text { Strike 3) } \\
\text { Poor lunch. } \\
\text { Strike 4) } \\
\text { delay. } \\
\text { Strike 5) } \\
\text { solo cross- } \\
\text { country } \\
\text { flight at } \\
\text { night. }\end{array}$ \\
\hline
\end{tabular}

There were two primary areas of inquiry for this research paper 1.) to identify reasons for the go/no-go decisions, and 2.) to identify fatigue mitigation strategies articulated by collegiate aviation pilots. A thematic analysis was conducted to provide a rich description of the data collected. According to Braun and Clark (2006) a thematic analysis is a foundational qualitative method for discovering patterns within the data. It should be conducted using a step by step process. The researchers first became thoroughly familiar with the data to 
generate initial codes. Upon the completion of coding the researchers discussed, came to agreement, then themes were generated.

As a final step, the researchers revised the themes and wrote the report. The researchers debated the strengths and weaknesses between strictly conceptualizing themes without quotes and heavily using quotes to provide readers with evidence. It was decided to merge the two philosophies and meet in the middle. Quotes were drawn from the data to allow readers to make their own judgements on credibility, accuracy, and fairness (Corden \& Sainsbury, 2006).

Initial examination of the scenarios was completed just as go-no-go decisions. The researchers were not necessarily interested in correct or incorrect responses. However, scenarios one, two, and four indicated a gap between go-nogo decisions. Scenarios three, five, and six were closer to evenly split. This indicates the scenarios provided the students with a decent mix of obvious go-nogo decisions and not so obvious decisions. This also indicates variation in the perceived risks among the sample population.

Two main themes developed from the explanatory free-text responses given by participants to explain Go decisions: External Pressures and Hazardous Attitudes. The FAA (2016) states:

External pressures are influences external to the flight that create a sense of pressure to complete a flight —often at the expense of safety. Factors that can be external pressures include the following:

- Someone waiting at the airport for the flight's arrival

- A passenger the pilot does not want to disappoint

- The desire to demonstrate pilot qualifications

- The desire to impress someone (probably the two most dangerous words in aviation are "Watch this!")

- The desire to satisfy a specific personal goal ("get-home-itis," "getthere-itis," and "let's-go-itis")

- The pilot's general goal-completion orientation. (p. 2-9)

After reviewing through the data, external pressures had three domains: organizational pressure, overreliance on another pilot i.e. CFI, and the inability to recognize hazardous attitudes. Some of the participants responded by stating the following which indicate organizational pressure:

"I would feel pressure to continue with the checkride since it has already been scheduled.";

"I know I'm not 100\% at my best, but honestly, I would still go. There's a lot of pressure- the examiner has scheduled time out of their day to take my checkride, and I don't want to waste their time." and;

"We are constantly under pressure to finish and delaying checkride might cause more headaches in the future."; 
These are well known pressures that have led to accidents in the general aviation, scheduled service, and military sectors. Specifically, organizational pressures are well documented and commonly reported by flight personnel (Adjekum, 2014; Adjekum et al., 2015; Adjekum et al., 2016). Understandably, collegiate flight programs need to flow students through the training pipeline. This pipeline is often disrupted by weather, aircraft maintenance, student and or instructor cancellations, shortage of designator examiners, and academic breaks. No program intentionally puts undue pressure on students and instructors in which they are to compromise safety. However, it is possible for students and instructors to internalize the explicit as well implicit goals which may influence decision-making.

Over reliance on another pilot or CFI was noted several times when respondents elected a go decision. Scenario four had the most go decisions that attributed to having another pilot onboard. Specifically, the responses seem to support the other pilot as being a CFI. This scenario set the conditions for chronic fatigue caused by family problems (CASA, 2012). A flight was to occur at 0730 after three nights of little sleep and acute stress. Several respondents indicated a go decision. These are instances of how respondents articulated overreliance on an instructor:

"Only if I'm going dual";

"I might not be flying at my best, but there will be an instructor to keep me safe and I'm sure that I'll still learn something either way";

"Flying with an instructor provides an increased margin of safety. I would let the instructor know of my situation before we fly and we can organize the lesson accordingly (perhaps focusing on low-stress maneuvers) It could still be a worthwhile lesson"; "provided there is an instructor aboard the plane. It is good to thoughtfully explore personal limits under proper supervision.";

"there is going to be an instructor with you so if it is a bad situation the instructor will take over."

The overreliance on an instructor is new information that was not highlighted in previous research. During the analyses, the researchers discussed under what conditions is this deemed appropriate reasoning. It is possible the pressure to get flights done trumps the decision-making. It also possible pilots going through training may build up a reliance on instructor during primary training. These responses make it apparent that some pilots lack the understanding of risks involved by over relying on another pilot or instructor. Two well-rested and fit pilots are the optimum situation to reduce risks. However, the tendency to assume the other pilot is fit to fly is concerning. 
Several respondents also indicated hazardous attitudes. Hazardous attitudes can manifest themselves in five primary ways: Anti-authority, Impulsivity, Invulnerability, Macho, and Resignation (FAA, 2016). When presented scenarios that induced acute and chronic fatigue, stress, physical and mental fatigue, respondents often articulated dangerous attitudes. Most of the responses fell into the invulnerability category. However, combinations of hazardous attitudes were indicated. Here are examples of hazardous attitudes within responses:

"As long as you feel ready, inadequate sleep for one night is not necessarily going to cause fatigue" (invulnerability);

"I typically function quite well without a lot of sleep; if I am wellprepared for my checkride then sleeping a bit less shouldn't affect me too much." (invulnerability);

"If I am not drinking, I will go ahead with my check ride. I am usually stressed before class exams but manage to do just fine on the exam. I am usually stressed before class exams but manage to do just fine on the exam." (invulnerability);

"I know my body and my mind well enough that I can fly competently and professionally, in a stressful environment, with three to five hours of sleep in a forty-eight-hour period" (invulnerability);

"I may feel completely capable to fly and perform the checkride despite a lack of rest"; (invulnerability);

"Flying is a good escape for me. When I'm up in the air, nothing on the ground matters" (invulnerability).

"Yes, I proceed because I don't want to be stranded at my location" (impulsivity-get-there-itis);

"Don't want to get stuck somewhere in the middle of nowhere." (impulsivity-get-there-itis) and;

"I need to get back." (impulsivity-get-there-itis) and;

"Flying will be a nice break after a bunch of physical work all day. I'm a flight instructor, so I work long days all the time. Let's fly!" (Macho/Invulnerability).

The inability to recognize hazardous attitudes may put pilots in a higher risk category particularly when it comes to night flights and the effects of circadian rhythms. The FAA (2016) provides several anecdotes for hazardous attitudes such as following the rules, think first-negative outcomes can happen to me, taking chances is foolish, and I am not helpless. These desirable thought patterns need to be trained and assessed by instructors as well as utilized for themselves. 


\section{Analysis of Fatigue Mitigation Strategies}

Identifying mitigation and alternative solutions during flight operations is a critical skill that will be required throughout career progression. Often, pilots operate in "gray" areas and professional judgment is required. Undesirable perceptions include Negative Threat Assessment without Seeking Alternatives and Positive Threat Assessment without Seeking Alternatives.

This section provides evidence about how collegiate aviation pilots might seek alternative decisions that may be appropriate. The primary theme and most desirable articulation were Positive Threat Assessment while Seeking Alternate Solutions. This theme provides the most desirable characteristic pilots can utilize during aeronautical decision-making. The first step is to recognize a threat exists and then find viable alternatives. This can be completed in an iterative process provided by decision-making models such as DECIDE, PAVE, and IMSAFE (FAA, 2016).

Articulated Positive Threat Assessment while Seeking Alternatives are shown with the following responses:

"I would go ahead and complete the oral portion of the checkride, but the flight portion should not be completed as you would be a danger to yourself and others, in addition to probably failing the checkride."

"During the time in which we waited, I would take a nap and use caffeine strategically before and during the flight."

"If you are tired, you are setting yourself up for failure. While you may be confident you are well prepared, you are tired, which could cause you to forget the information. Even though the weather isn't looking great for the scheduled date, it is still 7 days away and will probably change. Waiting would be the best thing to do in this case."

"Safety is more important than getting to the destination. I would find a place to rest and continue the flight after resting."

"no, but in a real situation I would have napped during the weather delay" "There isn't a ton of pressure to do this flight- I can tell my instructor I haven't slept well and want to do a sim or discussion instead or reschedule for later."

"ask to do a ground [lesson] instead of flying"

Ideally, well trained pilots should be able to recognize various threats and articulate alternatives on a consistent basis. An example of positive threat assessment without alternatives can be found in the following response, "Get home itis is a very real danger in this scenario and with the bad weather that was in the area, I would not risk it." This type of response can in fact save a student from an accident, incident, and or reduce risks. However, as pilots train to progress in their professional careers effective decision-making including 
alternatives should be prevalent in responses. The next section will provide an overview of the research project, discussion of results, and recommendations towards research, policy, and training.

\section{Discussion and Conclusion}

The researchers of this paper developed six fatigue-related decisionmaking scenarios and asked respondents to articulate the reasoning for each one. The primary focus during the analysis was to gain a clearer understanding of aeronautical decision-making processes and to examine the types of mitigation strategies within the synthetic operational environment. Currently, general aviation which includes collegiate aviation, is at its safest time period. From 2005 to 2016 , the accident rate steadily decreased from 7.97 accidents per 100,000 flight hours to 3.45 per 100,000 flight hours in 2016 (FAA, 2018). This is welcoming news for the general aviation community. However, there must be ongoing efforts to examine all areas of operations to reduce risks and make flying increasing sustainable. The results of this paper uncovered known and unknown problematic issues as well as desirable evidence of risk assessment and proper ADM.

Problematic issues included evidence that flight personnel still reported organizational pressures, overreliance on other pilots (i.e. instructors), and hazardous attitudes. Organizational pressure whether explicit or implicit is a challenge most flight training environments face. The researchers of this study who have been in both student and management roles find this issue to be most difficult to reconcile. However, it is suggested, as future research, to conduct a formalized approach utilizing interviews, focus groups, and surveys to develop a more comprehensive and validated list of best practices. A suggestion for best practices within collegiate aviation programs are outlined below. 
Table 3

Recommended practices for addressing organizational pressures

\begin{tabular}{|c|l|}
\hline Assessment & $\begin{array}{l}\text { Understand the pressures from student, instructor, and } \\
\text { management perspectives. Identify gaps in communication of } \\
\text { goals and seek to resolve issues that may compromise safety. }\end{array}$ \\
\hline Leverage & $\begin{array}{l}\text { Leverage accreditation bodies to gain access to resources for } \\
\text { proper staffing and resources. Lobby the FAA for additional } \\
\text { examiners to relieve bottlenecks and wait time. }\end{array}$ \\
\hline Review & $\begin{array}{l}\text { Periodically review scheduling of flight slots and consider } \\
\text { adjustments as student enrollment changes. Examine aircraft } \\
\text { utilization regularly to find underutilized flight slots. }\end{array}$ \\
\hline Culture & $\begin{array}{l}\text { Foster an environment that positively communicates goals, } \\
\text { solutions, and safety. }\end{array}$ \\
\hline Policy & $\begin{array}{l}\text { Develop mutually beneficial fatigue policies and incorporate } \\
\text { fatigue risk management tools and reporting systems. }\end{array}$ \\
\hline
\end{tabular}

Understanding the effects of fatigue and remedies as well as the over reliance on an instructor as well as the inability to recognize hazardous attitudes may be an indication of poor training and education. Sometimes respondents believed they could take a short nap to relieve chronic fatigue. However, research indicates "catching up" on sleep to relieve chronic fatigue with a nap is not enough (Caldwell \& Caldwell, 2016). Proper training and education regarding fatigue would lean more towards risk adverse decisions. Pilots should also have a thorough understanding of quality and quantity of sleep, circadian rhythms, acute, and chronic fatigue conditions. Furthermore, personal limitations should be established and articulated.

Though anecdotally, over reliance on another pilot such as an instructor was a new phenomenon from a research perspective that was not found explicitly in the literature. In fact, there were flight instructors who themselves reported undesirable attitudes and statements which indicated poor training and education. Conversations during the analysis revolved around professional conduct. Ideally, all pilots should exhibit professional behaviors so when combined in a team setting in order to produce optimal performance. Training and education in this context should revolve around personal excellence and not to shift lack of fitness to another pilot. It needs to be taught through scenario-based training and the review of accident case studies. Additionally, it should be assessed by instructors to highlight the importance of being fit. A good opportunity for pilots to learn how to avoid personal responsibility is during the teaching of aeronautical decision-making models. Though this was a small study, it is recommended that the FAA update training guidelines to include overreliance on another pilot as a threat. 
Hazardous attitudes are a well-known issue in professional cultures including pilots. These range from overconfidence to personality (Helmrich \& Merritt, 2001). However, there seems to be gaps in knowledge. Once again, proper training and education can be a valuable remedy (ICAO, 2013). Not only should instructors teach the hazardous attitudes, but also use scenario-based training. Additionally, examiners may use scenarios to identify gaps and create teachable moments. The Federal Aviation Administration (2017) updated testing standards and shifted from practical test standards (PTS) to Airmen Certification Standards (ACS) (FAA, 2017). According to the FAA (2017) one purpose of the ACS is to, "add task-specific knowledge and risk management elements to each PTS Area of Operation/Task. The result is an integrated presentation of specific knowledge, risk management, and skill elements for each Task (p. 3). In the ACS, hazardous attitudes are mentioned under the risk management category. Applicants need to be thoroughly examined in this area under various contexts. It may improve the preparation of applicants.

This report was not intended to be negative towards the general aviation community, organization, students, instructors, and management. There were several instances of applaudable responses. Several responses indicated the ability to identify threats and articulate adequate alternatives. The researchers of this study find this practice the most desirable which should be the goal of graduating students as they enter the workforce. To get to this goal, collegiate aviation pilots need to be taught that often sound aeronautical decision-making and professional judgement require a thought process. Regularly, even when conditions at face value may seem challenging, there is most likely a solution that has safety at forefront. Collegiate aviation pilots need to recognize that there may be a host of options such as strategic napping and caffeine use, healthy lifestyle choices, stress management, switching to a discussion lesson instead of cancelling all together, and time management. However, pilots need to be aware of the pitfalls particularly for the former in the previous list. According to the FAA (2016): Contrary to popular opinion, good judgment can be taught. Tradition held that good judgment was a natural by-product of experience, but as pilots continued to log accident-free flight hours, a corresponding increase of good judgment was assumed. Building upon the foundation of conventional decision-making, ADM enhances the process to decrease the probability of human error and increase the probability of a safe flight. (p.

This is the belief of the researchers as well. With concerted effort in corresponding ground courses, engaging teaching methods, and appropriate assessments. Over time it is predicted that respondents will articulate desirable decision-making explanations. One could assume that this will translate into desired behaviors in the operational environment. The positive benefits can 
provide an increase in learning, reduced risks, increased professionalism, and reduce the cost of training. After synthesizing the results, it is apparent there are many factors that can inhibit or promote positive decision-making. As stated, it is important for pilots to identify threats and seek alternate solutions. Illustration of the model is found in Figure 1.

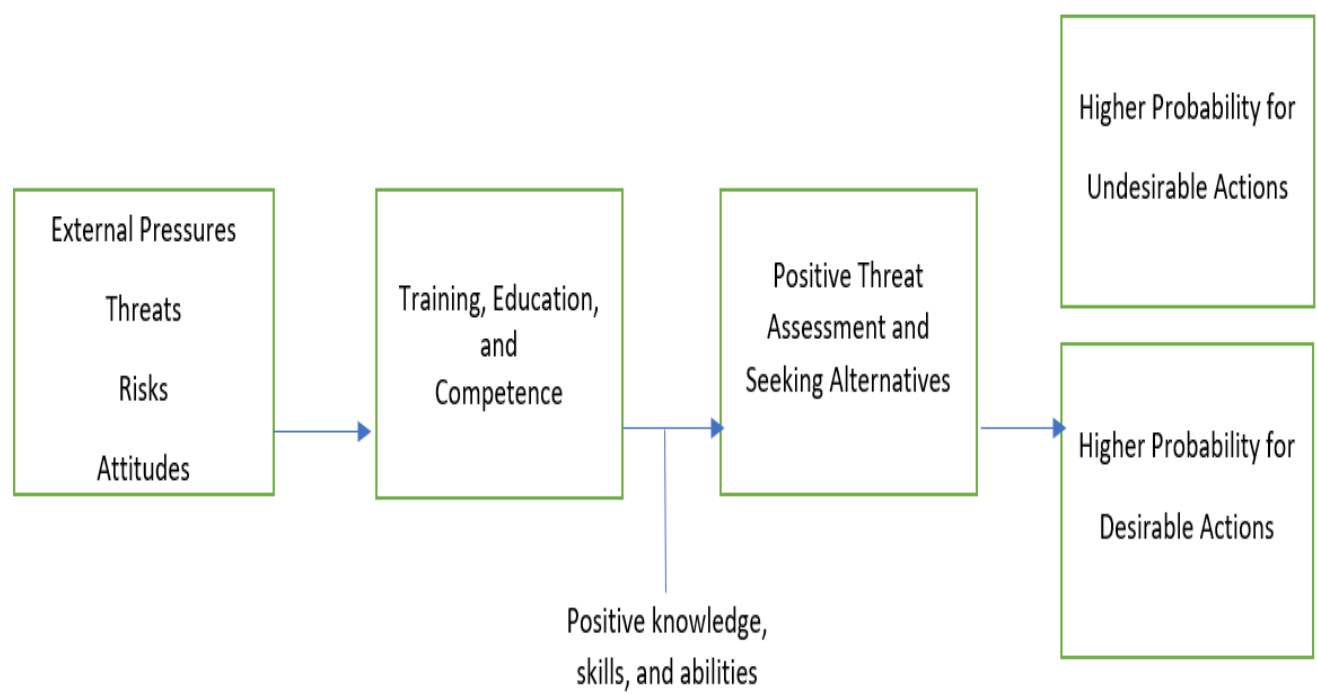

Figure 1. Aeronautical decision-making alternatives model (ADM-AM).

Prior to enrolling into flight training there are established pressures, threats, risks, and attitudes. These are established unwavering parts of an imperfect complex system. The training, education, and assessment process is intended to promote desired behaviors. Training, education, and demonstrated competence can shift attitudes, positively rationalize pressures, increase the understanding of risks as well as threats. If the training, education, and assessment is unfulfilled the probability of undesirable actions may increase. If the training, education, and assessments are positive then it is possible for a higher probability of desirable actions. Regarding seeking viable alternatives, it can be assumed the ease of the alternative may influence the decision-making process. The more difficult an alternative is to execute the more it may be disregarded. However, if pilots are trained to create numerous alternatives in the operational environment, it may be much easier to select a viable one. Additionally, the quality of alternatives can be trained and addressed. Though intuitive, this model can be tested through experimental designs under various contexts and provide additional evidence to aeronautical decision-making as well as decision-making overall. There is a plethora of research regarding decision-making, however, there seems to be an opportunity for further evaluation within the general aviation sector. This 
model, Aeronautical Decision-Making Alternatives Model (ADM-AM), may be useful with understanding the process and provide a basis for testing.

To conclude, after a review and analysis of responses from collegiate aviation pilots, there were strengths and weaknesses found. Recommendations were provided and a model for testing and iterations was proposed. Recommendations included best practices for management, scenario-based training, proper assessments, and future research. Though the results of this paper were limited by sample size and utilization of one flight program, the researchers hope the research community will continue research in this area. It is prudent for members to continue to examine this area not only for the ethical duty to reduce incidents and accidents but to foster learning as well as the associated benefits.

This study is the second of a series of data collection efforts which general goals were to evaluate collegiate aviation students' self-awareness of their fatigue issues, impact of fatigue on flight training quality and safety, and potential solutions (see Mendonca et al., in press). The next study will investigate the Part 141 collegiate aviation students' personal solutions to fatigue, workload, and how circadian rhythms affect their performance. In addition, researchers will assess if the pilots have received fatigue identification and management training and education. Limitations of the current study was it was conducted at one program. A continuance of research will be conducted to validate surveys, refine methodologies, best practices, and expansion to other programs. 


\section{References}

Adjekum, D. K. (2014). Safety culture perceptions in a collegiate aviation program: A systematic assessment. Journal of Aviation Technology and Engineering, 3(2), 44.

Adjekum, D. K., Keller, J., Walala, M., Young, J. P., Christensen, C., DeMik, R. J., \& Northam, G. J. (2015). Cross-sectional assessment of safety culture perceptions and safety behavior in collegiate aviation programs in the United States. International Journal of Aviation, Aeronautics, and Aerospace, 2(4), Article 3.

Adjekum, D. K., Keller, J., Walala, M., Christensen, C., DeMik, R. J., Young, J. P., \& Northam, G. J. (2016). An examination of the relationships between safety culture perceptions and safety reporting behavior among non-flight collegiate aviation majors. International Journal of Aviation, Aeronautics, and Aerospace, 3(3), Article 7.

Avers, K., \& Johnson, W. (2011). A review of Federal Aviation Administration fatigue research: Transitioning scientific results to the aviation industry. Aviation Psychology and Applied Human Factors, 1(2), 87-98.

Braun, V., \& Clarke, V. (2006). Using thematic analysis in psychology. Qualitative Research in Psychology, 3(2), 77-101.

Corden, A., \& Sainsbury, R., (2006). Using verbatim quotations in reporting qualitative social research: Researchers' views. Retrieved from https://www.kirklees.gov.uk/involve/document/AnalysingQualitativeData. pdf

Caldwell, J. A, Gilreath, S. R., Stephen R., Erickson, B. S., \& Smythe, N. K. (2000). Is fatigue a problem in Army aviation: The results of a survey of aviators and aircrews (USAARL Report No. 2001-03). Retrieved from https://pdfs.semanticscholar.org/ aaf5/a8fc7b317e026262a89bc60022018dac30ce.pdf

Caldwell, J., L., Hall, K. K., Prazinko, B. F., Norman, D. N., Rowe, T., Erickson, B. S., ... Caldwell, J. A. (2001). The efficacy of temazepam for improving daytime sleep and night-time performance in army aviators (USAARL Report No. 2002-05). Retrieved from http://www.dtic.mil/dtic/tr/fulltext/u2/a397776.pdf

Caldwell, J. A., \& Brown, C. L. (2003). Running' on empty? "Go Pills," fatigue and aviator safety. Flying Safety, 59(3), 4.

Caldwell, J. A. (2005). Fatigue in aviation. Travel Medicine and Infectious Disease 3(2), 85-96.

Caldwell, J. A., Mallis, M. M., Caldwell, J. L., Miller, J., Paul, M., \& Neri, D. (2009). Fatigue countermeasures in aviation. Aviation, Space, and Environmental Medicine, 80(1), 28-59. 
Caldwell, J. A., \& Caldwell, J. L. (2016). Fatigue in aviation: A guide to staying awake at the stick. NY, NY: Routledge.

Civil Aviation Safety Authority. (2012). Fatigue management strategies for aviation workers: A training \& development workbook. Retrieved from https://www.casa.gov.au/files/fatiguetoolkitstrategiespdf

Dawson, D., \& McCulloch, K. (2005). Managing fatigue: It's about sleep. Sleep Medicine Reviews, 9(5), 365-380.

Dawson, D., Chapman, J., \& Thomas, M. J. (2012). Fatigue-proofing: a new approach to reducing fatigue-related risk using the principles of error management. Sleep Medicine Reviews, 16(2), 167-175.

Federal Aviation Administration. (2007). Fatigue in aviation. Retrieved from https://www.faa.gov/pilots/safety/pilotsafetybrochures/media/Fatigue_Avi ation.pdf

Federal Aviation Administration. (2016). Pilot's handbook of aeronautical knowledge. Retrieved from https://www.faa.gov/regulations_policies/ handbooks_manuals/aviation/phak/

Federal Aviation Administration. (2018). Fact sheet: General aviation safety. Retrieved from https://www.faa.gov/news/fact_sheets/ news_story.cfm? newsId=21274

Federal Aviation Administration. (2017). Airmen certification standards briefing. Retrieved from https://www.faa.gov/training_testing/testing/acs/ media/acs_briefing.pdf

Fletcher, A., Hooper, B., Dunican, I., \& Kogi, K. (2015). Fatigue management in safety-critical operations: History, terminology, management system frameworks, and industry challenges. Reviews of human factors and ergonomics, 10(1), 6-28.

Flight Safety Foundation. (2009). Easing fatigue. Retrieved from https://flightsafety.org/asw/mar09/asw_mar09_p22-27.pdf

Gander, P. H., Mangie, J., Signal, T. L., Berg, M. J. V. D., Mulrine, H. M., Jay, S. M., \& Mangie, J. (2013). In-flight sleep, pilot fatigue and psychomotor vigilance task performance on ultra-long range versus long range flights. Journal of Sleep Research, 22(2), 697-706.

Greeley, H. P., Roma, P. G., Mallis, M. M., Hursh, S. R., Mead, A. M., \& Nesthus, T. E. (2013). Field study evaluation of cepstrum coefficient speech analysis for fatigue in aviation cabin crew (DOT/FAA/AM-13/19).

Retrieved from https://www.faa.gov/data_research/ research/ med_humanfacs/oamtechreports/2010s/media/201319.pdf

Goode, J. H. (2003). Are pilots at risk of accidents due to fatigue? Journal of Safety Research, 34(3), 309-313. 
Helmreich, R. L., \& Merritt, A. C. (2001). Culture at work in aviation and medicine: National, organizational and professional influences. London: Routledge.

Hockey, G. R. (1997). Compensatory control in the regulation of human performance under stress and high workload; A cognitiveenergetical framework. Biological Psychology, 45, 73-93. doi: 10.1016/S03010511(96)05223-4

Honn, K. A., Satterfield, B. C., McCauley, P., Caldwell, J. L., \& Van Dongen, H. P. (2016). Fatiguing effect of multiple take-offs and landings in regional airline operations. Accident Analysis \& Prevention, 86, 199-208.

International Civil Aviation Organization. (2012). Manual of civil aviation medicine (Doc. 8984-AN/895) (3rd ed.). Montreal, Canada: Author.

International Civil Aviation Organization. (2013). ICAO safety management manual (Doc. 9859-AN/474) (3rd ed.). Montreal, Canada: Author.

International Civil Aviation Organization. (2016). Fatigue risk management systems: Manual for regulators (Doc. 9966). Montreal, Canada: Author.

Kanfer, R., \& Ackerman, P. L. (1989). Motivation and cognitive abilities: An integrative/aptitude-treatment interaction approach to skill acquisition. Journal of Applied Psychology, 74, 657-690. doi:10.1037/00219010.74.4.657

Lee, S., \& Kim, J. K. (2018). Factors contributing to the risk of airline pilot fatigue. Journal of Air Transport Management, 67, 197-207.

Lorist, M. M., Klein, M., Nieuwenhuis, S., De Jong, R., Mulder, G., \& Meijman, T. F. (2000). Mental fatigue and task control: planning and preparation. Psychophysiology 37, 614-625. doi:10.1111/14698986.3750614

McDale, S., \& Ma, J. (2008). Effects of fatigue on flight training: A survey of U.S. Part 141 flight schools. International Journal of Applied Aviation Studies, 8(2), 311-336.

Meijman, T. (1991). Over Vermoeidheid: Arbeidspsychologische Studies Naar Beleving Van Belastingseffecten (Fatigue: Studies on the perception of workload effects). Dissertation, Amsterdam: University of Amsterdam.

Mendonca, F. A. C. M., Keller, J., \& Lu, C-T. (in press). Fatigue identification and management in flight training: An investigation of collegiate aviation pilots.

Miller, J. C., \& Melfi, M. L. (2006). Causes and effects of fatigue in experienced military aircrew. (AFRL-HE-BR-TR271). Retrieved from http://www.dtic.mil/dtic/tr/fulltext/u2/a462989.pdf

National Transportation Safety Board. (2019). Most wanted list archive. Retrieved from https://www.ntsb.gov/safety/mwl/pages/mwl_archive.aspx

Palmer, L. (2013). The relationship between stress, fatigue, and cognitive functioning. College Student Journal, 47(2), 312-325. 
Petrie, K. J., \& Dawson, A. G. (1997). Symptoms of fatigue and coping strategies in international pilots. The International Journal of Aviation Psychology, 7(3), 251-258.

Petrie, K. J., Powell, D., \& Broadbent, E. (2004). Fatigue self-management strategies and reported fatigue in international pilots. Ergonomics, 47(5), 461-468.

Rosekind, M. R., Graeber, R. C., Dinges, D. F., Connell, L., Rountree, M. S., Spinweber, C. L., \& Gillen, K. A. (1992). Crew factors in flight operations IX. Effects of preplanned cockpit rest on crew performance and alertness in long-haul operations (NASA Technical Memorandum 108839). Retrieved from https://ntrs.nasa.gov/search.jsp?R=19950006379

Sieberichs, S., \& Kluge, A. (2016). Good sleep quality and ways to control fatigue risks in aviation-An empirical study with commercial airline pilots. In Advances in Physical Ergonomics and Human Factors (pp. 191201). Springer, Cham.

Tassi, P., \& Muzet, A. (2000). Sleep inertia. Sleep medicine reviews, 4(4), 341353.

van der Linden, D. (2011). The urge to stop: The cognitive and biological nature of acute mental fatigue. In P. L. Ackerman (Ed.), Cognitive Fatigue: Multidisciplinary Perspectives on Current Research and Future Applications, 149-64. http://dx.doi.org/10.1037/12343-007

Williamson, A. M., \& Feyer, A. M. (2000). Moderate sleep deprivation produces impairments in cognitive and motor performance equivalent to legally prescribed levels of alcohol intoxication. Occupational and Environmental Medicine, 57(10), 649-655. 